The University of Maine

\title{
DigitalCommons@UMaine
}

Maine-Syracuse Longitudinal Papers

Maine-Syracuse Longitudinal Study

1979

\section{Relationship of age and hypertension to neuropsychological test performance}

Clyde A. Pentz III

Merrill F. Elias

University of Maine - Main, mfelias@maine.edu

W Gibson Wood

Norman A. Schultz

John Dineen

Follow this and additional works at: https://digitalcommons.library.umaine.edu/ longitudinal_papers

Part of the Cardiovascular System Commons, and the Cognitive Psychology Commons

\section{Repository Citation}

Pentz, C. A., Elias, M. F., Wood, W. G., Schultz, N. A., \& Dineen, J. (1979). Relationship of age and hypertension to neuropsychological test performance. Experimental aging research, 5(4), 351-372.

This Article is brought to you for free and open access by DigitalCommons@UMaine. It has been accepted for inclusion in Maine-Syracuse Longitudinal Papers by an authorized administrator of DigitalCommons@UMaine. For more information, please contact um.library.technical.services@maine.edu. 


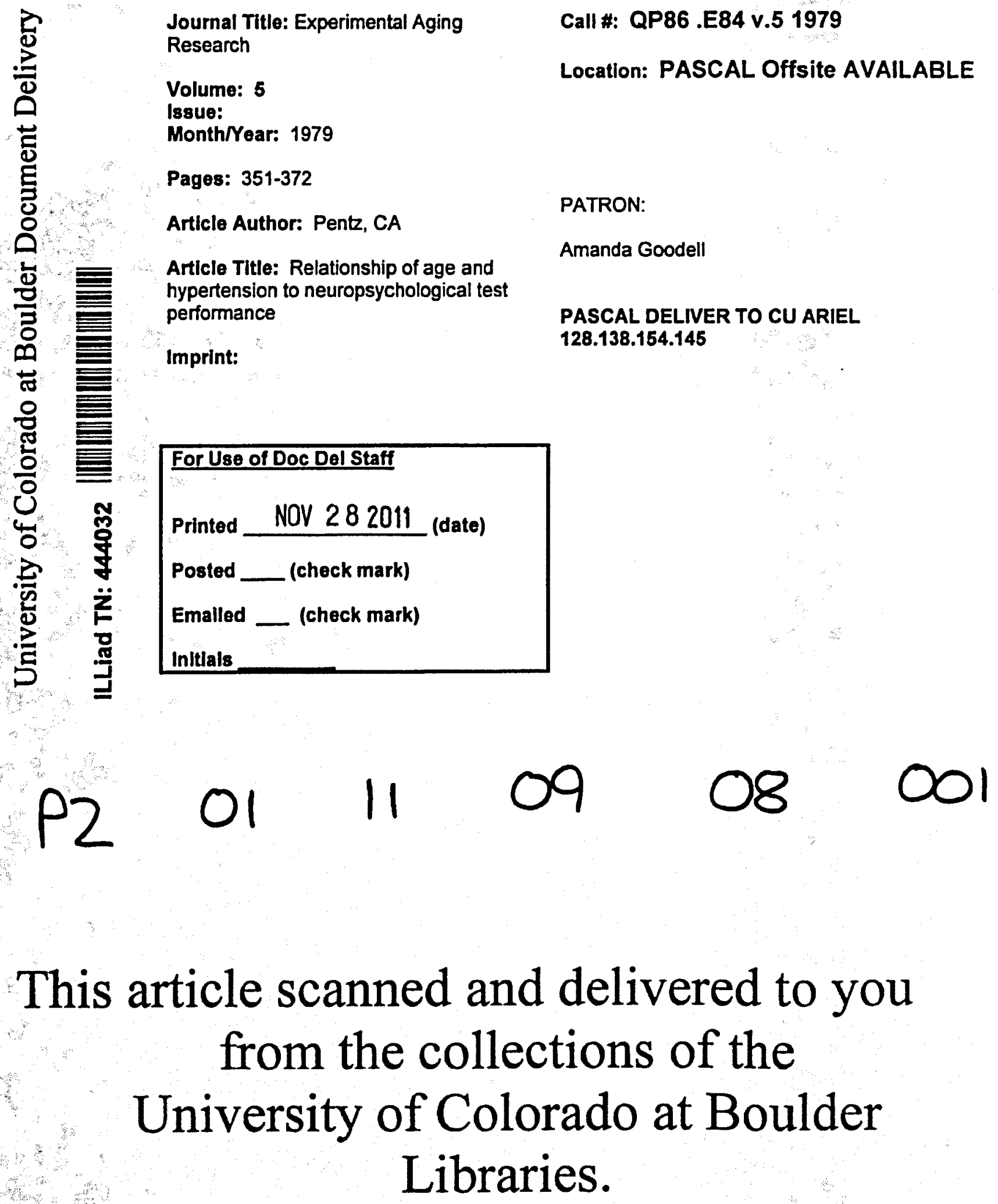




\section{RELATIONSHIP OF AGE AND HYPERTENSION TO NEUROPSYCHOLOGICAL TEST PERFORMANCE}

\author{
CLYDE A. PENTZ, III \\ Division of Individual and Family Studies \\ The Pennsylvania State University \\ University Park, Pennsylvania 16802 \\ U.S.A. \\ W. GIBSON WOOD \\ Bangor Mental Health Institute \\ Bangor, Maine 0440I \\ U.S.A.
}

\author{
MERRILL F. ELIAS \\ Department of Psychology \\ University of Maine at Orono \\ Orono, Maine 04469 \\ U.S.A.
}

NORMAN A. SCHULTZ

Department of Psychology

Clemson University

Clemson, South Carolina 29631

U.S.A.

\section{JOHN DINEEN}

Department of Psychology

Syracuse University

Syracuse, New York 13210

U.S.A.

Pentz, C.A. , Elias, M.F., Wood, W.G., Schultz, N.A., \& Dineen, J. Relationship of age and hypertension to neuropsychological test performance. Experimental Aging Research, 1979, $5(4), 351-372$. Young adult $(\bar{X}=29)$ and middle aged $(\bar{X}=$ 50) hypertensive and normutensive subjects were compared with respect to seven neuropsychological test scores derived from tests on the Halstead-Reitan battery. Age main effects, with inferior performance for the middle aged subjects, were observed for the localization and time portions of the Tactile Performance Test (TPT) and for the Trail Making A test. The multivariate age effect was significant for the composite of seven scores. A multivariate blood pressure main effect was obtained and main effect blood pressure was significant for the category test; hypertensives made more errors than normotensives. A blood pressure by age interaction was observed for finger tapping scores and the TPT-Memory scores with larger differences between hypertensives and normotensives for the younger than for the middle aged group. Results were discussed in terms of previous studies of age and hypertension with the WAIS, the Primary Mental Abilities Test and serial reaction time measures. The poor prediction of hypertensive status from individual neuropsychological test scores was emphasized and readers were cautioned not to conclude that essential hypertensives, as a group, can be characterized as brain damaged.

This study was supported by a Grant from the National Institute on Aging to M.F. Elias (AG 00868). Reprint requests should be sent to M.F. Elias. M.F. Elias is also af filiated with Bangor Mental Health Institute and W.G. Wood is also affiliated with the Department of Psychology, University of Maine at Orono. 
Beginning with studies by Birren and Spieth (1962) and Spieth (1965), increasing attention has been focused on the effects of hypertension on the cognitive behavior and psychomotor performance of middle-aged and elderly subjects. Spieth, for example, found that for middle-aged subjects (35 to 59 years), untreated (non-medicated) essential hypertensives performed less well than normotensive controls when a composite time score was derived from serial reaction time tasks, the WAIS digit symbol subtest, and the WAIS block design subtest. However, medicated hypertensives did not differ from the controls with respect to this composite measure.

More recently, Light (1975) compared three age groups of subjects (18-31 years; $32-45$ years; $46-59$ years) with respect to serial reaction time tasks. She found that medicated hypertensives (not on medication at the time of testing) performed more poorly than normotensive subjects and non-medicated hypertensives, but the latter two groups did not differ.

In an earlier longitudinal study of WAIS performance, Wilkie and Eisdorfer (1971) found that hypertension, associated with end-organ pathology, was related to significant intellectual loss over a ten year period for subjects who were initially examined between age 60 and 70 . Recently, we began a series of studies designed to determine whether younger and middle-aged hypertensive subjects differ with regard to WAIS scores and other tests that have been found to be useful in clinical-diagnostic contexts. In the first of these studies, Schultz, Dineen, Elias, Pentz, and Wood (1979) compared Verbal and Performance WAIS scores for highly educated essential hypertensive and normotensive controls using a cross-sectional design. Although, hypertensives performed more poorly than normotensive for a younger (21-39 years) and older group (45-65 years), differences between hypertensive subjects and normotensive subjects were more exaggerated for the younger group.

The present study was conducted in parallel with the WAIS sturiv using subiects from that study who volunteered to come to 
our laboratory for more extensive testing on selected neuropsychological tests from the Halstead-Reitan battery. These tests were used in the present experiment because they have been shown to be particularly sensitive to cognitive dysfunction and perceptual motor impairment.

There are data indicating that hypertensive subjects perform poorly on tests from the Halstead-Reitan battery (Apter, Halstead \& Heimberger, 1951; Goldman, Kleinman, Snow, Bidus, \& Korol, 1974), but comparisons of different age groups of well educated essential hypertensive subjects and well educated and medically screened normotensive subjects have not been undertaken with neuropsychological tests. The presence of a hypertensive diagnostic clinic adjacent to our laboratory provided us with the opportunity to compare young and middle-aged hypertensive and normotensive subjects on a number of tests from the Halstead-Reitan battery. The question raised in the present experiment was whether well educated essential hypertensives (hypertensive free from hypertensionassociated pathology) would differ from well educated normotensives and whether differences between these two groups would be more exaggerated for the middle-aged than for the younger subjects. Our previous study with the WAIS had not been completed at the time subjects were recruited for this study. Consequently, no specific hypotheses were advanced regarding the interaction of hypertension and age. However, based on the data for hypertension and neuropsychological test performance (cited above), and the general finding of poorer neuropsychological test performance for older than for younger subjects (see Klisz, 1978, for a review), we did hypothesize: 1) poorer test performance for hypertensives than for normotensives and 2) poorer performance for older than for younger subjects.

The present study was not designed to determine whether hypertensive subjects are brain damaged based on HalsteadReitan neuropsychological test scores. Rather, the tests were used in order to characterize the performance of different age 
groups of hypertensive and normotensives on tests commonly used in diagnostic evaluation.

\section{METHOD}

Subjects

Three groups of men and women served as subjects: examined hypertensive subjects, examined normotensive subjects, and non-examined normotensive subjects. Hypertensive subjects $(n=25)$ and examined normotensives $(n=16)$ were paid volunteers that had participated in a previous study of WAIS performance (Schultz et al., 1979). Both groups had been examined medically in connection with a series of studies on hypertension and plasma renin activity at Upstate Medical Center, State University of New York (see Streeten, Anderson, Freiberg, \& Dalakos, 1975). The examined normotensives were not patients, but had taken part in the plasma activity studies as normotensive controls. The range of times between examination at the Upstate Medical Center Clinic and testing in our laboratory was 1 day to 38 days for the younger subjects $(\bar{X}=12$ days) and 1 day to 34 days $(\bar{X}=12$ days $)$ for the older subjects.

Results of the medical examination, including physical examination, EKG, and medical history, were used to eliminate hypertensive patients and examined controls with the following medical histories or symptoms: cerebral vascular accident, congestive heart failure, coronary heart disease, angina pectoris, kidney failure, type II or III eye ground changes and improper use of medication. Using the standard ascultatory method, five blood pressure recordings were taken in a sitting position in our laboratory during testing. However, all hypertensive subjects in this study had been diagnosed as hypertensive by their physicians and the diagnosis had been confirmed by medical examination and multiple standing and recumbant blood pressure recordings at the Upstate Medical Center Clinic. Subjects in both age groups carried diagnoses ranging from mild to severe essential hypertension, but the majority fell in the first 
two categories. Subjects were assigned to the essential hypertensive groups if they exhibited none of the histories or symptoms listed above and if their blood pressure values exceeded 140/90 $\mathrm{mm} \mathrm{Hg}$ during the examination at the Upstate Medical Center Clinic and at the time of testing in our laboratory.

Blood chemistry analyses, obtained in the context of plasma renin activity (PRA) studies at Upstate Medical Center, provided information on the PRA levels for hypertensive and examined control subjects. Preliminary analyses of variance indicated no significant performance differences among high $(>8.5 \mathrm{ng} / \mathrm{ml} / \mathrm{hr})$, low $(<1.7 \mathrm{ng} / \mathrm{ml} / \mathrm{hr})$, and normal PRA subjects $(1.7 \mathrm{ng} / \mathrm{ml} / \mathrm{hr}-8.5 \mathrm{ng} / \mathrm{ml} / \mathrm{hr})$ for any of the dependent variables $\left(p_{\mathrm{S}}>0.283\right)$. Thus, high and low PRA subjects were not eliminated from the sample. We were not primarily concerned with the relationship of PRA level to performance scores in the present study, but these data were recorded for each subject because Light (1975) reported a blood pressure by PRA interaction in a study of serial reaction time.

Twenty-one non-examined normotensive controls were obtained from the community. They were paid volunteers who had participated in WAIS testing previous to this experiment. This group was not examined medically but all subjects in it displayed normal blood pressure values (systolic and diastolic blood pressure values less than $140 \mathrm{~mm} \mathrm{Hg}$ and $85 \mathrm{~mm} \mathrm{Hg}$ respectively). In addition, these non-examined controls did not differ from the examined controls with respect to symptoms reported on the Cornell Medical Index (Wood, Elias, Schultz \& Pentz, 1978). Both groups scored in the normal range. Examined and non-examined controls did not differ with respect to any of the behavioral measures or education level. Thus, the two groups were combined into a single normotensive control group $(n=$ 37 ). None of the normotensive subjects were taking medication and they all exhibited blood pressures less than $140 / 85 \mathrm{~mm} \mathrm{Hg}$ at the time of testing. 
At the time of testing, seven (7) hypertensives had been placed on medication and eighteen (18) had not yet been placed on medication. These two groups were equated with respect to mean diastolic blood pressure values calculated from recordings at the Upstate Medical Center Clinic under circumstances in which both groups had been removed from medication for 3 to 21 days. Consistent with our studies with the WAIS (Schultz et al., 1979), no significant differences in performance were obtained for these two groups for any of the behavioral measures or for education level. Thus, these subjects were combined into a single hypertensive group $(n=25)$.

Table 1 summarizes the number of subjects in each age and blood pressure group, systolic, diastolic and mean arterial blood pressure ( $\mathrm{mm} \mathrm{Hg}$ ), age, education, and scaled scores from the previous administration of the WAIS on the day of the medical examination at Upstate Medical Center. Blood pressures reported are those obtained in our laboratory at the time of behavioral testing.

\section{Procedure}

Only five tests from the Halstead-Reitan battery were administered because subject time was limited. The tests chosen were among those in the battery that are most sensitive to neuropsychological impairment and have been used in studies of aging (see Klisz, 1978) and hypertension (e.g., Spieth, 1965; Goldman et al., 1974; Apter et al., 1951). A prorated impairment index can be computed from these tests. The five tests were administered in the following order: Category Test; Finger Oscillation Test (finger tapping); Tactual Performance Test (time, localization, and memory components); Trail Making Test A; Trail Making Test B. Standard testing procedures were followed. These tests have been very widely used in clinical assessment and details of the testing procedure have been provided elsewhere (Halstead, 1974; Reitan, 1955). Briefly, the Category Test is the single most sensitive test of brain impairment (Reitan, 1955). It involves concept formation and the ability to form learning sets. The 


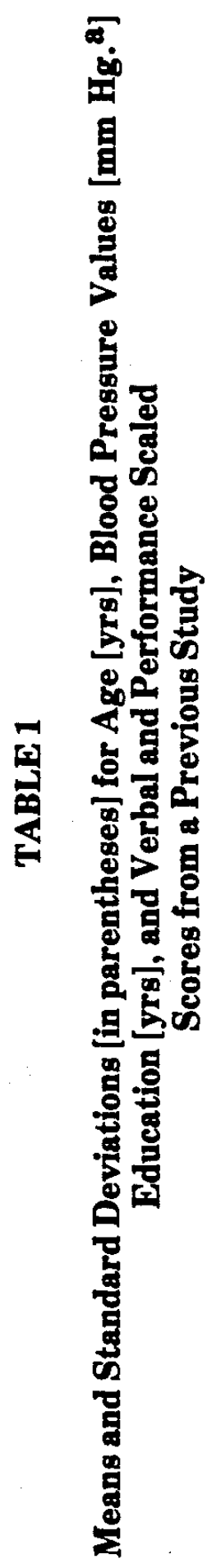

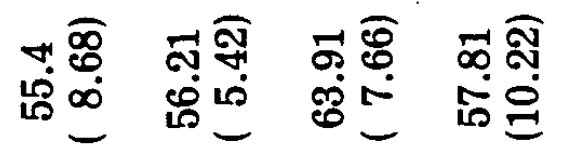

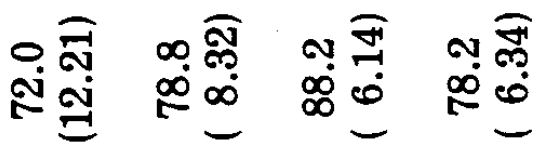

年云 曷

蛋导

:

$\stackrel{\circ}{4}$

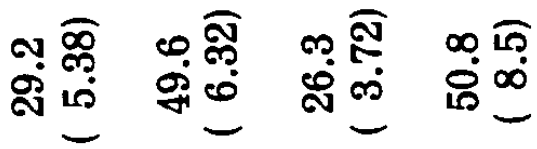

ิㅗㅇ

(2)

:

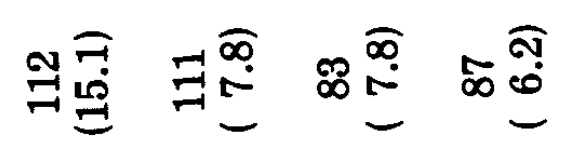

ธㄷํㄹํ \&

茖

点

芦

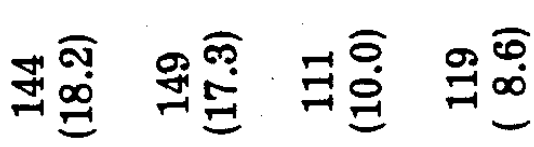

兽

ह

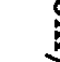

离

$\varliminf_{\infty}^{\infty} \leqslant \infty_{\infty}^{\infty} \stackrel{\sim}{\sigma}$

$\exists \quad \nexists$

$\stackrel{a}{1}$

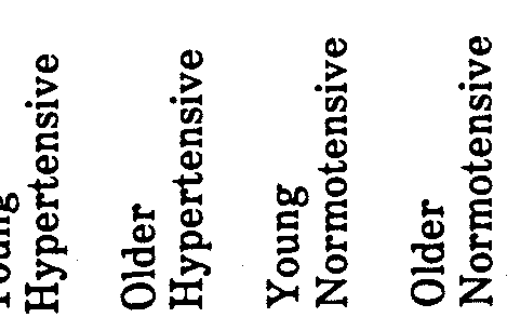

| 
subject was presented with 208 stimulus figures via a projector. After viewing a set of four figures, the subject was asked to indicate which of the four possible figures was correct. Correctness was based on stimulus dimensions, e.g., number, position, size, shape, color, which change throughout the series. Positive feedback was presented by a bell and negative feedback by a buzzer. The total number of errors on seven sub-tests was recorded.

The Tactual Performance Test (TPT) used a modified form of the Sequin-Goddard form board. The subject was blindfolded and instructed to fit shapes into their proper spaces on the board. A score (time in seconds) was obtained for the preferred hand, the non-preferred hand and both hands. The sum of these three scores was used as a total time score. When this portion of the task was completed, the board and blocks were taken to another room, the blindfold removed, and the subject was asked to draw a diagram of the board representing the blocks in their proper places. Scores (0 to 10 ) for number of blocks recalled (memory) and correct placements in space (localization) were obtained.

For the Finger Oscillation Test (tapping), the subject was given five consecutive ten second trials in which he/she tapped as rapidly as possible using the index of the preferred hand and then the non-preferred hand. The mean of five scores (no more than five taps apart) was obtained. Mean number of taps for the preferred hand was used as the performance score.

For the Trail Making A Test, the subject was required to connect, in consecutive order, numbers that were placed in various positions on a paper. For Trail Making $B$ Test, the subject was required to connect numbers and letters, e.g., 1-A-2-B-3-C, etc. Time (in seconds) to complete parts $A$ and $B$ was recorded.

In addition to these five tests (seven scores), a prorated Impairment Index (I.I.) was computed. This was the ratio of 
tests for which scores were in the "brain impairment range" /tests administered. Normally ten (10) tests are used to compute the index, but as few as five scores may be employed. In this study five of the scores normally comprising the index were used: Category errors, TPT-Time, TPT-Memory, TPTLocalization, and finger tapping.

\section{Design}

A 2 (blood pressure groups) by 2 (age groups) factorial design was used. Nonorthogonal analyses of variance were performed with MANOVA (Clyde Computing Company, 1969). MANOVA uses the Wilk's lambda criterion (Rao's approximate $F$ test) to perform the multivariate test of main effects and interactions. Preliminary anàlyses indicated no significant interaction of gender with other factors and thus scores for males and females were combined. For significant $F$ ratios, measures of strength of association between experimental conditions and the dependent variable $\left(\omega^{2}\right)$ were obtained (Hays; 1963, p. 407).

\section{RESULTS}

Table 2 summarizes results of analysis of variance of education level and WAIS scores. The age by blood pressure interaction was statistically significant $\left(p<0.001, \omega^{2}=0.17\right)$ for the Verbal scaled scores on the WAIS. It is clear from inspection of Table 1 that the younger normotensives were superior to the other groups. Blood pressure main effects were significant for education $\left(p<0.05, \omega^{2}=0.06\right)$, Verbal $\left(p<0.05, \omega^{2}=0.10\right)$ and Performance WAIS scores $\left(p<0.05, \dot{\omega}^{2}=0.07\right)$. Hypertensive subjects exhibited a slightly lower education level and lower WAIS Performance scores when scores were averaged over age groups.

Table 3 summarizes analyses of variance for the seven (7) neuropsychological test scores. Table 4 summarizes mean and standard deviations for each dependant variable. 


\section{TABLE 2}

Results of Analysis of Variance (F ratios) for Education Level and WAIS Verbal and Performance Scaled Scores Obtained in a Previous Experiment

$\begin{array}{llcc}\begin{array}{l}\text { Blood Pressure } \\ \text { Group (BPG) } \\ (d f=1,58)\end{array} & 5.26^{*} & 9.72^{* *} & 4.05^{*} \\ \begin{array}{l}\text { Age (A) } \\ (d f=1,58)\end{array} & 1.32 & 2.15 & \\ \text { BPG X A } & & & 2.60 \\ (d f=1,58) & 2.05 & 15.60^{* *} & 2.30 \\ \end{array}$

$* p<0.05$

${ }^{* *} p<0.01$

Multivariate main effects were significant for both the blood pressure $(p<0.02)$ and the age $(p<0.02)$ main effects, but the age by blood pressure interaction did not reach statistical significance $(p>0.05)$. Nevertheless, the trends within each age group cannot be ignored in the interpretation of the significant main effects and interactions for univariate analyses of variance.

The blood pressure main effect was significant for errors on the Category Test $\left(p<0.05, \omega^{2}=0.01\right)$. The blood pressure by age interaction did not reach significance $(p>0.14)$, even though differences between hypertensive and normotensive subjects were more exaggerated for the younger (Table 4) than for the older group.

A significant blood pressure by age interaction $(p<0.05$, $\omega^{2}=0.09$ ) was observed for finger tapping scores but absolute 


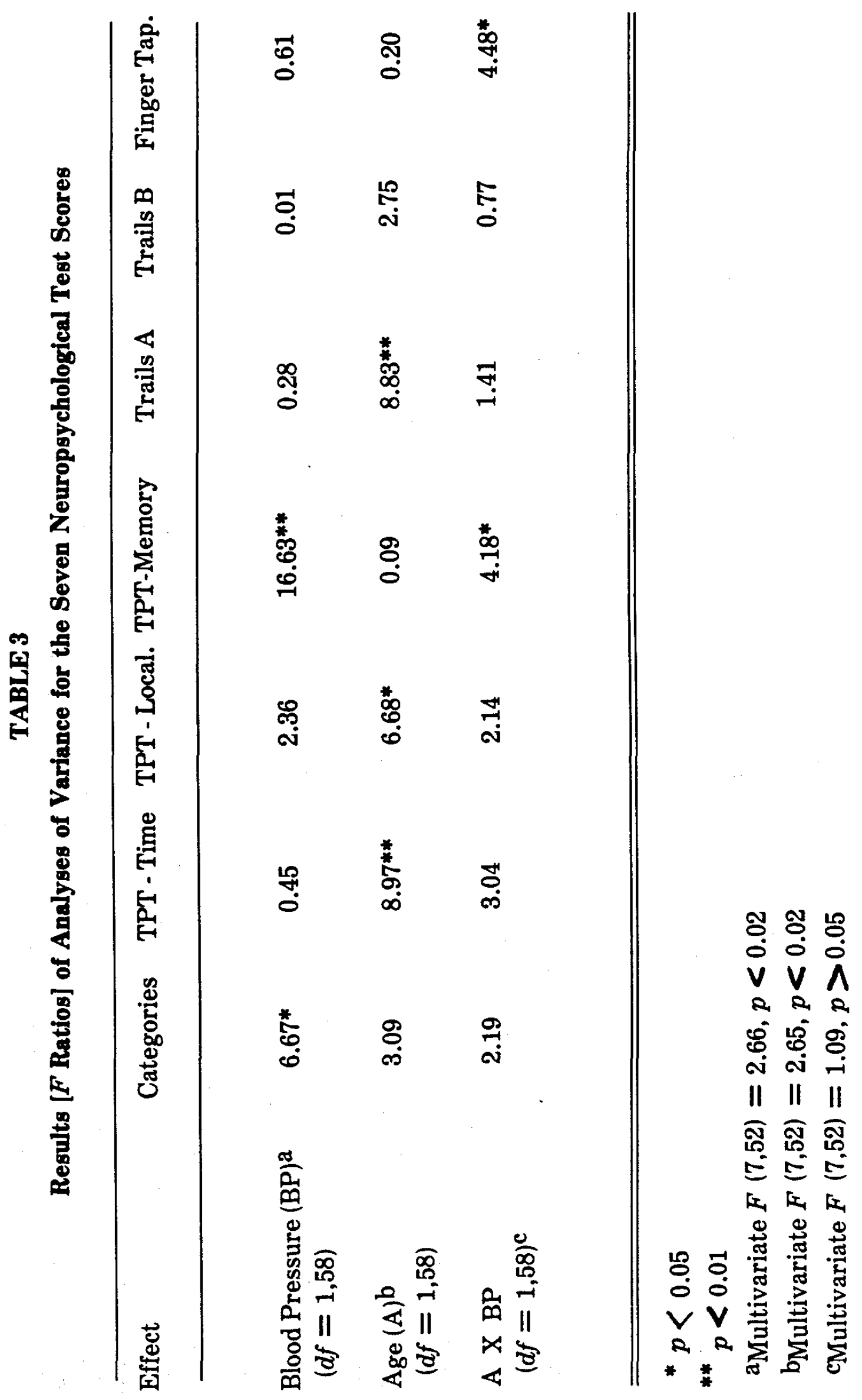




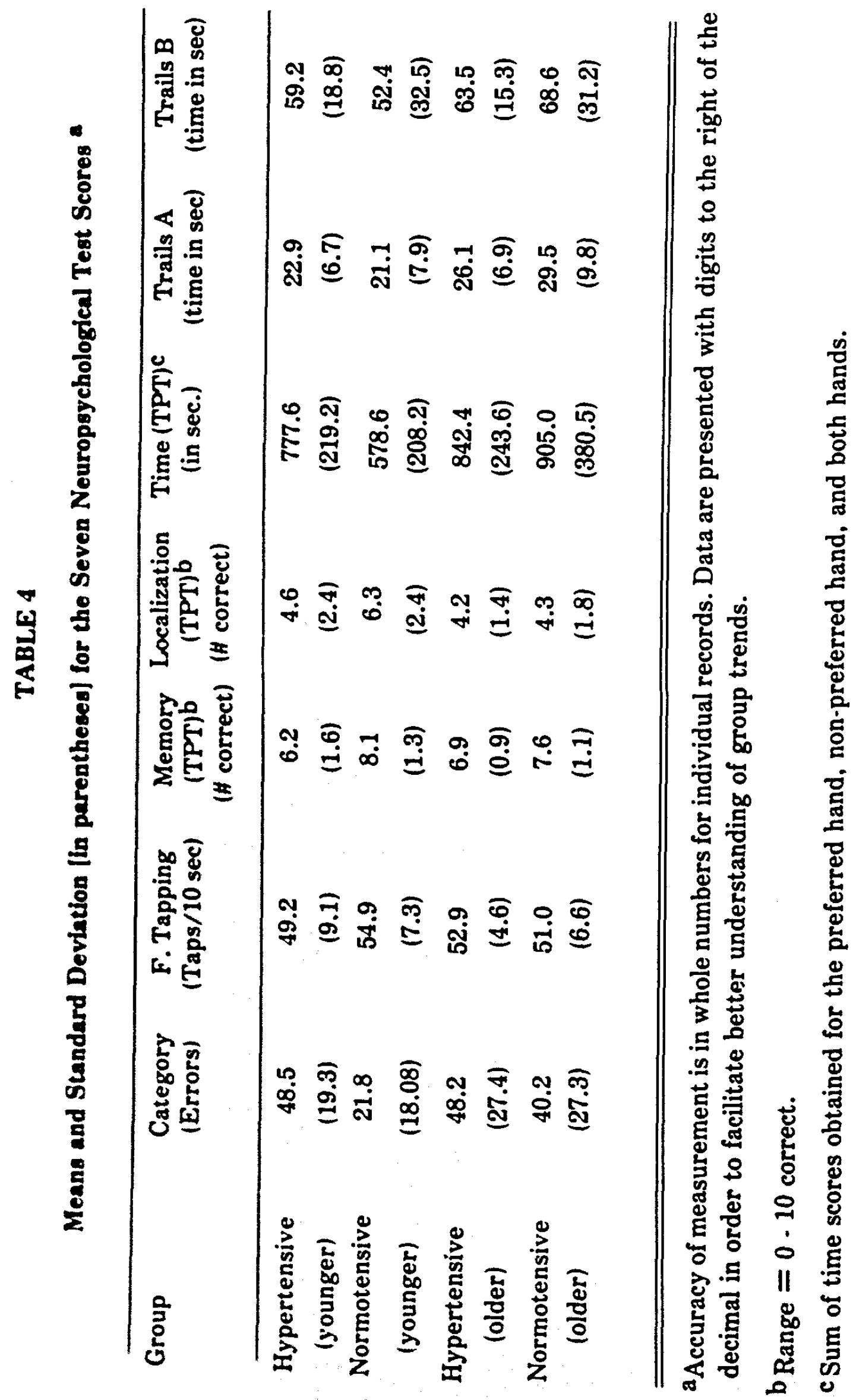




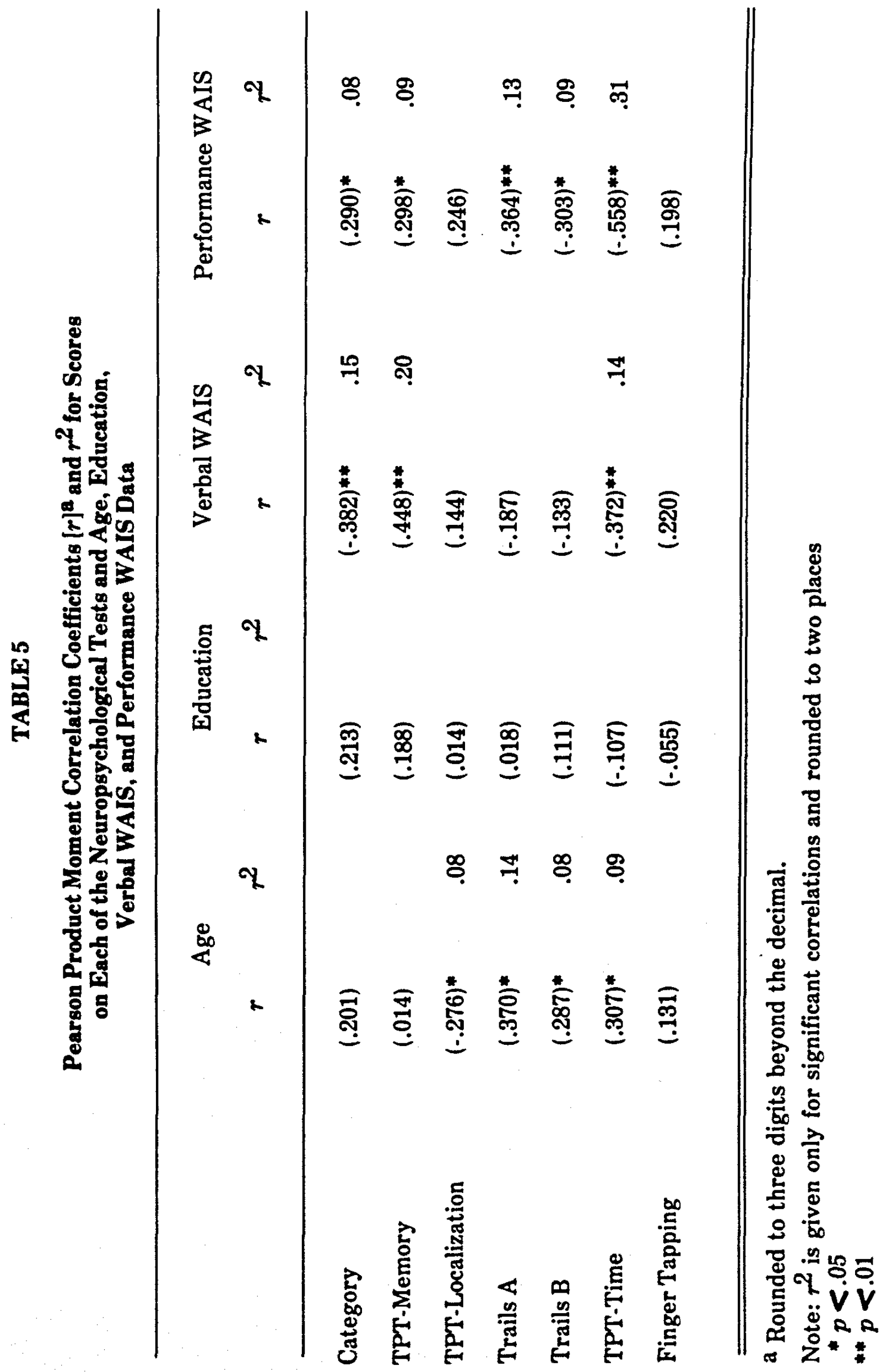


differences between hypertensives and normotensives for young and old groups were trivial.

The blood pressure main effect $\left(p<0.01, \omega^{2}=0.31\right.$ and the blood pressure by age interaction were significant $(p<0.05$, $\omega^{2}=0.05$ ) for the TPT-Memory scores. It may be seen in Table 4 that differences between blood pressure groups for TPTMemory scores were slightly more exaggerated for the younger than for the older subjects, although tests of simple main effects indicated significant differences between hypertensives and controls for younger $(p<0.002)$ and for the older $(p<0.05)$ subjects.

Significant age main effects were observed for the TPT-Time score $\left(p<0.01, \omega^{2} 2=0.11\right)$, the TPT-Localization score $\left(p<0.05, \omega^{2}=0.10\right)$ and the Trail Making A test score $(p<0.01$, $\omega^{2}=0.10$ ). In each case the older subjects performed more poorly than the younger subjects. Inspection of Table 4 suggests a blood pressure by age interaction for TPT-Time scores. This interaction did not reach significance at $p<0.05,(p=0.09)$. The age main effect and the blood pressure main effect were not significant for the Impairment Index. The age by blood pressure interaction was also non significant.

In summary, there was a general trend for differences between means for hypertensives versus normotensives to be more exaggerated for the younger than for the older subjects. This was largely related to the fact that the younger normotensives were superior in performance for all of the measures. However, only two age by blood pressure interactions reached significance at $p<0.05$, i.e., TPT-Memory and finger tapping scores.

Table 5 summarizes Pearson Product moment correlation coefficients $(r)$ and $r^{2}$ between each of the neuropsychological test and age, education level, and WAIS scores. Age correlated significantly with TPT-Localization scores, Trails A and B 
scores, and TPT-Time scores. No correlations involving education level were significant. Verbal scaled scores correlated significantly with Category scores, TPT-Memory scores, and TPT-Time scores; Performance scaled scores correlated significantly with Category scores, TPT-Memory scores, TPT-Time scores, and Trails A and B scores. It may be seen (Table 5) that Performance WAIS scores shared the largest percent common variance with TPT-Time scores (31\%) and Verbal WAIS scores shared the largest perecent common variance with TPT-Memory scores $(20 \%)$. In most cases, $r^{2}$ were small or $r$ was not significant.

\section{DISCUSSION}

Three of the neuropsychological tests, and a multivariate composite score made up the the seven test scores, revealed peformance trends consistent with the hypothesis of impaired neuropsychological test peformance for the middle aged as compared to the younger subjects. The multivariate $F$ was significant for the age main effect and for three of the univariate tests of the age main effect, TPT-localization, TPT-time, and Trails A. No blood pressure main effects or interactions with blood pressure were observed for these three tests. Age differences have been observed for all of the tests selected for this study (see Klisz, 1978 for a review). The fact that significant age main effects were observed for only three of the tests may be related to the fact that elderly subjects were not used and subjects were well educated and healthy, with the exception of hypertensive symptoms. Age by blood pressure interactions (discussed later) were observed for the Finger Oscillation and the TPT-Memory scores.

Consistent with a previous finding of a significant positive correlation between errors on the category test and diastolic blood pressure values (Goldman et al., 1974), hypertensive subjects made more errors on the Category Test than normoten- 
sive subjects. The greatest difference between hypertensive and normotensive groups was observed for the younger age group and was largely related to superior performance of the younger normotensives. However, the age by blood pressure interaction did not reach statistical significance. Given this finding and the large standard deviations observed, it would be highly desirable to repeat the study of Category Test performance with a larger number of subjects before reaching the conclusion that age by blood pressure interactions do, or do not, exist for this measure of cognitive performance.

An age by blood pressure interaction was obtained for two of the tests (TPT-Memory and Finger Oscillation). In both cases, differences between means for hypertensives and normotensives were more exaggerated for the younger than for the older group. It should be pointed out that absolute differences in means were small for both measures. However, in the case of the memory scores, the small differences between means is related to the fact that range of possible scores is quite limited (0 to 10). Data for the TPT-Memory Test and the Finger Oscillation Test are consistent with our findings that hypertensives performed less well than normotensives on the WAIS with more exaggerated differences for the younger subjects (Schultz et al., 1979). In retrospect, it is not surprising to find that the results of this study and the WAIS study (with a larger $n$ ) parallel each other in some respects. Subjects from the present study represent a subsample of subjects from the WAIS study who volunteered to come to our laboratory for more extensive testing. Data from the WAIS study had not been analyzed when subjects in this study were tested.

Data for the WAIS reported in the present study, and for the larger sample from which these WAIS data were obtained (Schultz et al., 1979), are generally consistent with Wilkie and Eisdorfer's finding of hypertension-associated decrements on the WAIS. However, Wilkie and Eisdorfer's data indicate that the effects of hypertension are exacerbated by increasing age and 
present data do not. These findings do not reflect inconsistencies in results because the two studies are not comparable. Wilkie and Eisdorfer used a longitudinal study and much older subjects, many with hypertension-related pathologies. In the second test-retest period of their study, involving subjects $\mathbf{7 0}$ years and older at initial testing, both borderline hypertensives and normotensive subjects showed a decline over a ten year period with the greater decline for the borderline hypertensive group. None of the hypertensive subjects over 70 at initial testing survived the study. It is important that the present study with young adult- and middle aged-essential hypertensive subjects not be interpreted as contradicting the notion that hypertension and age can interact in a deleterious manner with respect to cognitive processes.

In view of the age by blood pressure interaction for WAIS Verbal scores and the blood pressure main effect for WAIS Performance scores (Table 2), a question may be raised as to whether some of our findings for neuropsychological test scores might not be due to differences in general level of intelligence. The question cannot be resolved by covarying WAIS scores from the neuropsychological test scores. A reduction in the discriminative ability of the neuropsychological tests would prove nothing other than the two sets of tests measure some common intellective factors. The most important information can be gained from inspection of the $r^{2}$ values in Table 5 . Here it may be seen that the largest $r^{2}$ values were obtained for Verbal WAIS scores and TPT-Memory scores (.20) and for Performance WAIS scores and TPT-Time scores (.31). Other correlations were either not significant or $r^{2}$ values were low (ranging from .09 to .15). These data suggest that the conclusion that neuropsychological test scores merely reflect group differences in general intellective functioning (as inferred from the WAIS) is not justified. On the other hand, it does not come as a surprise that WAIS scores and neuropsychological test scores reflect some common intellective processes (see Heaton et al., 1978). 
Findings for the TPT-Memory scores are consistent with a report of poorer performance by hypertensives than by normotensives on sub-sections of the Wechsler Memory Scale (Wilkie, Eisdorfer, \& Nowlin, 1976). These investigators suggested that anxiety or difficulties in shifting set, rather than memory per se, may explain their findings. Wood, Elias, Schultz, and Pentz (1978) have reported slightly (but statistically significant) higher state anxiety and depression scores for hypertensive than for normotensive subjects. However, these anxiety and depression scores were not in a clinically significant range and analyses of these data for subjects in the present study indicated very low and non-significant correlations among anxiety, depression scores and neuropsychological test scores ( $r$ 's range $=\mathbf{- 0 . 0 6 0}$ to -0.117). The learning set hypothesis is deserving of further investigation.

Differences in education level do not appear to explain the present findings. The regressions of education on neuropsychological test scores were all non-significant. At present we have no explanation for the greater differences between younger normotensives and hypertensives than between older hypertensives and normotensives for the Finger Tapping and TPTMemory scores. Examination of the medical records did not indicate differences between the young and old groups in the classes of drugs administered, i.e., tranquilizers, diuretics, vasodilators, sympathetic inhibitors, or combinations thereof, and no class of drugs appeared to be associated with poorer performance than another. The wide range of drugs and doses used made formal analysis of individual drug effects impossible.

Although the pattern of more exaggerated differences between hypertensives and normotensives for younger than for older subjects may reflect sampling artifacts, there are data suggesting that these differences may reflect distinctive aging patterns for some performance measures. We (Schultz et al., 1979 ) found more exaggerated differences between hypertensive 
and normotensive subjects for younger than for older subjects in our cross sectional WAIS study with the larger sample of subjects from Upstate Medical Center. Hertzog, Schaie, and Gribbin (1978) found performance increments on several subtests of the Primary Mental Abilities test when 56 year old hypertensives were retested seven years later. Normotensives showed decrements on the same longitudinal comparisons. Several investigators have suggested that mildly elevated blood pressure may serve to help maintain cognitive function with advanced age (Obrist, 1964; Wilkie \& Eisdorfer, 1973; Wang \& Busse, 1974).

In contrast to findings for serial reaction time by Spieth (1965) and Light (1976), medicated and non-medicated hypertensives did not differ with respect to any of the neuropsychological tests. However, the studies differ in several major ways. In contrast to the present study, Spieth's medicated subjects were all reduced to normal or near normal blood pressure values at the time of testing and hypertensives and controlled hypertensives may have been experiencing differential levels of stress with regard to the implications of successful blood pressure management for future employment as air traffic controllers or pilots.

In Light's study, hypertensives were tested under the influence of a potent diuretic and the medicated group of hypertensives had been removed from medication 3 to 7 days prior to treatment. In the present study, the medicated group was actually medicated at the time of treatment and was not tested under the influence of a potent diuretic. However, we (Schultz et al., 1979) did not find differences between medicated and non-medicated hypertensives for the WAIS study, and they were tested under the influence of a potent diuretic. Different tasks may be differentially sensitive to medication.

In contrast to Light's (1975) findings for serial reaction time, significant differences within hypertensive groups were not 
obtained for a preliminary data analysis involving high, low, and normal plasma renin activity groups. This may have related to the fact that varying intervals from 1 to 38 days between PRA measurement and testing were characteristic of our subjects. On the other hand, Light (1978) failed to repeat her initial findings of a PRA effect in a second study, and we (Schultz et, al., 1979) failed to find a PRA effect for our study in which WAIS data were collected on the same day that blood samples were collected for PRA analysis.

Although our findings are consistent with previous findings that hypertension is associated with poor performance on neuropsychological tests (Reitan, 1954; Goldman et al., 1974), particularly the Category Test from the Halstead-Reitan battery (Goldman et al., 1974), it would be most inappropriate to conclude that the relatively highly educated and intelligent essential hypertensive patients who participated in the present experiment were brain damaged. Firstly, we have no relevant brain-damage cut-off scores for the population of subjects from which this sample was obtained. Secondly, individual differences were very large for several of the tests (e.g., errors on the Category Test and the times portion of TPT). For example, on the Category test, $12(48 \%)$ hypertensive subjects scored in the normal range with respect to Reitan's cut-off scores ( $\leq 50$ errors) while $8(22 \%)$ normotensive subjects scored in the brain damaged range. These data and the fact that very low measures of association $\left(\omega^{2}\right)$ for the main effects and interactions indicate that prediction of age or essential hypertensive status on the basis of individual test scores cannot be accomplished with a reasonable degree of clinical accuracy. We are not suggesting that the possibility of brain dysfunction for individual subjects in normotensive or hypertensive groups can be "ruled out" by our data. We do suggest that it is not proper to characterize hypertensives as brain damaged simply because they perform more poorly (as a group) than normotensive subjects on some neuropsychological tests. 
In summary, it should be emphasized that there has been a consistent pattern of results reported in various papers generated by the current hypertension project (Schultz et al., 1979; Wood, et al., 1978; Wood, Elias, Schultz \& Pentz, 1978). In each instance, deficits shown by hypertensives for some tests were greater at younger than at older age levels. However, there is considerable uncertainty as to which factors might be contributing to this phenomenon. Cross-sectional sampling procedures and the common identity of most subjects employed across these studies may account for the effect in terms of some type of sampling artifact. Alternatively, studies such as those by Hertzog et al. (1978) support the position that the interaction may represent varying developmental trends, dependent on cardiovascular status. At this juncture there is simply not enough data available to allow unequivocal conclusions to be drawn concerning this phenomenon. It is suggested that long-term longitudinal follow-ups with the current subject population, in which each subject's cardiovascular status is monitored (as in Hertzog, et al., 1978), may eventually establish whether the current results, and other (e.g., Hertzog, et al., 1978; Schultz, et al., 1979) represent design artifacts or true developmental differences across age groups differing in cardiovascular status.

\section{REFERENCES}

APTER, N.S., HALSTEAD, W.C., HEIMBURGER, R.F. Impaired cerebral functions in essential hypertension. Psychiatry, 1951, (107), 808-813.

BIRREN, J.E. \& SPIETH, W. Age, response speed and cardiovascular functions. Journal of Gerontology, 1962, (17) 390-391.

CLYDE, D.J. Multivariate analysis of variance on large computers. Miami; Clyde Computing Service, 1969.

ELIAS, M.F. Potential applications of multivariate analysis of variance to psychpharmacological research. In B.E. Eleftheriou (Ed.), Psychopahramaco-genetics. New York: Plenum Press, 1975, 435-465.

GOLDMAN, H., KLEINMAN, K.M., SNOW, M.Y., BIDUS, D.R., \& KOROL, B. Correlation of diastolic blood pressure and signs of cognitive dysfunction in essential hypertension. Diseases of the nervous system, 1974, (35), 571-572.

GUYTON, A.C. Textbook of medical physiology. Philadelphia: W.B. Saunders Company, 1971. 
HALSTEAD, W.C. Brain and intelligence: A quantitative study of the frontal lobes. Chicago: University of Chicago Press, 1947.

HAYS, W.J. Statistics. New York: Holt, Reinhart \& Winston, 1963.

HEATON, R.K., BAADE, L.E., \& JOHNSON, K.L. Neuropsychological test results associated with psychiatric disorders. Psychological Bulletin, 1978, (85), 141-162.

HERTZOG, C., SCHAIE, K.W., \& GRIBBIN, K. Cardiovascular diseases and changes in intellectual functioning from middle to old age. Journal of Gerontology, 1978, (33), 872-833.

KLISZ, D. Neuropsychological evaluation in older persons. In M. Storandt, I.C. Siegler, \& M.F. Elias (Eds.) The clinical psychology of aging. New York: Plenum Press, 1978, pp 71-97.

LIGHT, K.C. Effects of mild cardiovascular and cerebrovascular disorders on serial reaction time performance. Experimental Aging Research, 1978, 4, (1), 3-22.

LIGHT, K.C. Slowing of response time in young and middle-aged hypertensive patients. Experimental Aging Research, 1975, (1), 209-228.

OBRIST, W.D. Cerebral ischemia and the senescent electroencephalogram. In E. Simonson \& T.H. McGavack (Eds.), Cerebral ischemia. Charles C. Thomas: Springfield, IL., 1964.

REITAN, R.M. The validity of the Trail Making Test as an indicator of organic brain damage. Perceptual \& Motor Skills, 1958, (8), 271-276.

REITAN, R.M. An investigation of the validity of Halstead's measures of biological intelligence. Archives of Neurological Psychiatry, 1955, (73), 28-55.

REITAN, R.M. Intellectual and affective changes in essential hypertension. American Journal of Psychiatry, 1954, (110), 817-824.

SCHULTZ, N.R., DINEEN, J.T., ELIAS, M.F., PENTZ, C.A., III, \& WOOD, W.G. WAIS performance for different age groups of hypertensive and control subjects during administration of a diuretic. Journal of Gerontology, 1979, (34), 246-253.

SPIETH, W. Slowness of task performance and cardiovascular disease. In A.T. Welford, \& J.E. Birren (Eds.) Behavior, aging and the nervous system. Springfield: C.C. Thomas, 1965.

STREETEN, D.H.P., ANDERSON, G.H., FREIBERG, J.M., \& DALAKOS, T.G. Use of an angiotensin Il antagonist (Saralasin) in the recognition of "angiotensinognic" hypertension, New England Journal of Medicine, 1975, (292), 657-662.

WANG, H.S., \& BUSSE, E.W. Heart disease and brain impairment among aged persons. In E. Palmore (Ed.), Normal aging II. Duke Univ. Press, Durham, N.C., 1974.

WILKIE, F.L., EISDORFER, C. \& NOWLIN, J.B. Memory and blood pressure in the aged. Experimental Aging Research, 1976, (2), 3-16.

WILKIE, F.L., \& EISDORFER, C. Systemic disease and behavioral correlates. In L. Jarvik, C. Eisdorfer \& J. Blum (Eds.), Intellectual functioning in adults; Psychological and biological influences. Springer: New York, 1973.

WILKIE, F. \& EISDORFER, C. Intelligence and blood pressure in the aged. Science, 1971, (72), 959-962.

WOOD, W.G., ELIAS, M.F., SCHULTZ, N.R., \& PENTZ, C.A., III. Symptoms reported on the Cornell Medical Index in relationship to hypertension and age. Experimental Aging Research, 1978, (4), 21-433.

WOOD, W.G., ELIAS, M.F., SCHULTZ, N.R., PENTZ, C.A. Anxiety and depression in young and middle aged hypertensive and normotensive subjects. Experimental Aging $R e$ search, 1979, (5), 15-30. 